\title{
Para reatar Ulisses: \\ a judicialização da política como mastro garantidor dos pré-compromissos constitucionais*
}

Sandro Luís Tomás Ballande Romanelli

\section{Resumo}

A partir da Constituição da República Federativa do Brasil de 1988, a ampliação dos instrumentos de proteção judicial e da acomodação de um maior número de interesses e orientações levou ao protagonismo dos tribunais. É desse ponto que este estudo faz uma revisão bibliográfica no campo do direito constitucional e da ciência política para estudar os limites da legitimidade do Poder Judiciário quando atua ativamente na alocação de recursos públicos. Aborda-se principalmente a questão do método jurídico e sua incapacidade de produzir unidade social, já que sua esfera decisional independe do consenso político. São expostas algumas das soluções apontadas pela Ciência Política e pelo Constitucionalismo contemporâneo à questão, buscando o diálogo entre os aportes de Jon Elster e de George Tsebelis em suas análises das Instituições Políticas com as teorias constitucionais que tratam da democratização do Poder Judiciário, mais especialmente, em Peter Häberle e sua teoria sobre a sociedade aberta dos intérpretes da constituição. Nesse aspecto, o estudo da judicialização como um canal de debate ou reivindicação política envolve diretamente as questões do atual arranjo democrático (pós-88) e a busca de legitimidade (ou representatividade) do Poder Judiciário.

Palavras-chave: Judicialização da política. Protagonismo judicial. Democracia.

\footnotetext{
No original (Federalist Papers no 78): "The judiciary, on the contrary, has no influence over either the sword or the purse; no direction either of the strength or of the wealth of the society; and can take no active resolution whatever. It may truly be said to have neither force nor will, but merely judgment [...]."

1 Mestrando em Direitos Humanos e Democracia na UFPR e professor no Instituto Federal de Educação, Ciência e Tecnologia do Paraná - IFPR.
} 


\section{Introdução}

O judiciário [...] não tem influência nem sobre a espada, nem sobre a bolsa; tampouco pode direcionar a força ou a riqueza da sociedade e não toma nenhuma iniciativa por conta própria. Em verdade, pode-se dizer que não tem nem força, nem vontade, mas apenas julgamento $[\ldots] .^{2}$

A frase acima, extraída de um dos artigos da série hoje conhecida como Federalist Papers, foi publicada na imprensa de Nova York em junho de 1788. Expõe claramente a absorção das ideias de Montesquieu de que o Poder Legislativo deveria ser separado do Poder Executivo e, mais especialmente, separado do Poder Judiciário (o poder de resolver conflitos aplicando regras pré-existentes).

Desde aquele tempo, as instituições foram modificadas e hoje a separação das funções do Estado já não é absoluta. Matthew M. Taylor afirma que, embora o conceito da separação dos poderes conduza a três instituições claramente distintas:

As funções judiciais, legislativas e executivas dessas instituições não são caprichosamente separadas em nítidas caixas institucionais como às vezes supomos. Existe uma sobreposição das funções das três instituições [...] diante da qual não é de surpreender que o Judiciário tenha algum efeito no processo de formação de políticas públicas. ${ }^{3}$

A despeito da distância temporal e das modificações institucionais, ainda há muitos defensores afirmando que a separação absoluta seria a única a impedir a tirania.

O presente artigo advoga em sentido contrário.

A influência do Judiciário na elaboração e aplicação de políticas públicas tem sido ativa. Há pelo menos meio século já se reconhece que o Judiciário pre-

${ }^{2}$ HAMILTON, Alexander. The Federalist n. 78: the judiciary department. Independent Journal, 14 Jun. 1788. Disponível em: <http://www.constitution.org/fed/federa78.htm>. Acesso em: 10 ago. 2010.

3 TAYLOR, Matthew Macleod. O Judiciário e as políticas públicas no Brasil. Revista Dados, Rio de Janeiro, v. 50, n. 2, 2007. Disponível em: <www.scielo.br/pdf/dados/v50n2/ a01v50n2.pdf $>$. Acesso em: 14 ago. 2010. 
enche um papel político como uma instituição "para a tomada das decisões sobre questões controversas da política nacional”. ${ }^{4}$

Como se expõe no presente trabalho, defende-se que essa participação é salutar para manter os pré-compromissos constitucionais estabelecidos na Constituição, além de dar voz aos atores excluídos da arena legislativa ordinária. O Judiciário funciona, assim, como ágora entendida.

\section{0 protagonismo dos tribunais}

Para situar temporalmente a questão, no Brasil, a partir da Constituição de 1988, as transformações constitucionais permitiram o maior protagonismo dos tribunais em virtude da ampliação dos instrumentos de proteção judicial, mecanismos que Luis Werneck Vianna afirma terem sido recentemente descobertos e crescentemente utilizados por minorias parlamentares, governos estaduais, associações civis e profissionais. ${ }^{5}$

Eis um pequeno panorama do protagonismo do Poder Judiciário colhido por Matthew M. Taylor:

Nos 15 anos entre 1988 e 2002, o STF - somente através do instrumento da Ação Direta de Inconstitucionalidade - Adin - concedeu decisões liminares ou de mérito invalidando parcialmente mais de $\mathbf{2 0 0}$ leis federais. [...] Mesmo no governo de Fernando Henrique Cardoso - um presidente apoiado (pelo menos inicialmente) por uma ampla coalizão reformista -, o Judiciário federal como um todo foi convocado por atores externos para julgar todas as principais políticas públicas adotadas pelo Executivo e seus aliados no Congresso. [...] As mais significativas e reais ameaças às reformas surgiram no Judiciário e não no Legislativo: das $\mathbf{1 0}$ principais iniciativas políticas

4 DAHL, Robert 1957 apud TAYLOR, Matthew Macleod. O judiciário e as políticas públicas no Brasil. Revista Dados, Rio de Janeiro, v. 50, n. 2, 2007. Disponível em: <www.scielo.br/ pdf/dados/v50n2/a01v50n2.pdf>. Acesso em: 14 ago. 2010.

5 VIANNA, Luís Werneck et al.A judicialização da política e das relações sociais no Brasil. Rio de Janeiro: Revan, 1999. 
aprovadas durante o governo Fernando Henrique, todas foram contestadas de alguma forma pelo Judiciário, e sete das 10 foram alteradas ou atrasadas de alguma maneira no STF. ${ }^{6}$

Na medida em que o legislativo cede parte de suas atribuições ao judiciário, ocorre o fenômeno da derrogação política, ${ }^{7}$ transferindo o embate político para as deliberações nos tribunais, o que Thais Florêncio de Aguiar chama de "descaracterização do modelo político do Estado moderno", ${ }^{8}$ acarretando no declínio da confiança nos parlamentos e no descrédito dos políticos.

Tal fenômeno denota uma inversão da arena eleita para o debate. Explica-se: uma vez que o Poder Legislativo, tanto por conta da percepção de que as instituições legislativas estão imobilizadas (culpa do método majoritário, no qual o consenso é raramente encontrado), quanto em razão dos casos de corrupção que maculam sua imagem e reputação, ${ }^{9}$ não consegue solucionar conflitos e tensões entre as diferentes tendências existentes nas sociedades, o espaço para o debate - tornado embate, haja vista a polarização em partes opostas - passa a ser a arena do Poder Judiciário.

No conjunto dos Três Poderes, o judiciário emerge com a relevância de um "terceiro gigante" ${ }^{10}$ assumindo funções que ultrapassam a de simples guardião do pacto constitucional e contrapeso aos outros poderes, ${ }^{11}$ passando a efetivo órgão

6 TAYLOR, Matthew Macleod. O judiciário e as políticas públicas no Brasil. Revista Dados, Rio de Janeiro, v. 50, n. 2, 2007. Disponível em: <www.scielo.br/pdf/dados/v50n2/ a01v50n2.pdf $>$. Acesso em: 14 ago.2010.

7 Tal conceito é explicitado por Mauro CAPPELETTI “[...] nota-se que o poder legislativo tem delegado decisões ao poder judiciário por razões como a elaboração de leis vagas e ambíguas, a falta de fôlego e a pouca perícia técnica para atuar a cada mudança de quadro" CAPPELLETTI, Mauro. Juízes legisladores? Tradução Carlos Álvaro de Oliveira. Porto Alegre: S. A. Fabris, 1999.

8 AGUIAR, Thais Florencio de. A judicialização da política ou o rearranjo da democracia liberal. Revista eletrônica semestral do programa de estudos pós-graduados em ciências sociais da PUC-São Paulo, São Paulo, n. 2, Semestral, 2007.

9 AGUIAR, Thais Florencio de. A judicialização da política ou o rearranjo da democracia liberal. Revista eletrônica semestral do programa de estudos pós-graduados em ciências sociais da PUC-São Paulo, São Paulo, n. 2, Semestral, 2007.

${ }^{10}$ CAPPELLETTI, Mauro. Juízes legisladores? Traduçao Carlos Álvaro de Oliveira. Porto Alegre: S. A. Fabris, 1999.

${ }^{11}$ TATE, Neal; VALLINDER, Torbjorn. The global expansion of judicial power. New York: New York University, 1995. 
de correção em instância final, eis que as tensões não resolvidas na arena legislativa podem ser - e crescentemente o são - levadas ao judiciário sob o manto da garantia constitucional da inafastabilidade do Poder Judiciário. ${ }^{12}$

\section{A judicialização da política}

Parte da literatura vem descrevendo o fenômeno do protagonismo dos tribunais como "judicialização da política" ${ }^{13} \mathrm{O}$ termo implica na transferência do embate político e de políticas públicas para as deliberações nos tribunais.

Para Marcus Faro de Castro a judicialização da política ocorre quando as questões políticas passam a ser decididas na arena jurídica: "Em decorrência do papel do Poder Judiciário, especialmente do STF, na salvaguarda da Constituição e na tutela dos direitos individuais e coletivos, tem-se verificado no Brasil a judicialização de questões políticas que passaram a ter nos órgãos jurisdicionais a sua instância decisória final”." ${ }^{14}$

Além de descrever a expansão da jurisdição dos tribunais sobre as esferas dos poderes Legislativo e Executivo, Tate e Vallinder tratam da judicialização enquanto adoção do método judicial, de qualidade argumentativa (e não da maioria), para o ambiente político. Isso ocorre pela adesão no campo político, do método judiciário como vetor de resolução de conflitos: ${ }^{15}$

${ }^{12}$ Conforme a redação do art. $5^{\circ}$, XXXV da Constituição Federal.

${ }^{13}$ É interessante observar que o termo já é encontrado há mais de uma década em estudos de cientistas políticos (os trabalhos de Werneck Vianna e Marcus Faro de Castro são de 1997), mas é raramente encontrada na literatura jurídica. Nesta, o fenômeno é algumas vezes descrito como ativismo judicial, embora não seja um sinônimo, eis que usualmente empregado para descrever negativamente o excesso de liberdade decisional dos magistrados.

${ }^{14}$ CASTRO, Marcus Faro de. O Supremo Tribunal Federal e a judicialização da política. Revista Brasileira de Ciências Sociais, São Paulo, v. 12, n. 34, p. 147-156, jul.1997.

${ }^{15}$ AGUIAR, Thais Florencio de. A judicialização da política ou o rearranjo da democracia liberal. Revista eletrônica semestral do programa de estudos pós-graduados em ciências sociais da PUC-São Paulo, São Paulo, n. 2, Semestral, 2007. 
Assim, a judicialização da política deve normalmente significar: (1) a expansão da jurisdição dos tribunais ou dos juízes a expensas dos políticos e/ou dos administradores, isto é, a transferência de direitos de tomada de decisão da legislatura, do gabinete ou da administração pública para os tribunais, ou, pelo menos, (2) a propagação dos métodos de decisão judiciais fora da jurisdição propriamente dita. Em resumo, podemos dizer que a judicialização envolve essencialmente transformar algo em processo judicial ${ }^{16}$

Como observa Thais Florêncio de Aguiar, a judicialização da política pode ter outras duas facetas, a das demandas das minorias legislativas (transformando o Poder Judiciário em palco dos embates entre a situação e a oposição) e a da justiça eleitoral, não só zelando sobre a lisura da disputa eleitoral, mas estabelecendo regras e remodelando indiretamente a lei eleitoral:

Essa judicialização da política manifesta-se também no uso dos tribunais e Cortes constitucionais até mesmo por políticos de oposição e partidos que, abandonando os púlpitos legislativos, lançam mão do poder judiciário para se opor às iniciativas do governo ou mesmo obstruí-las. Com efeito, a judicialização atinge inclusive a classe política, sobre a qual se pressupunha vigorar a arte do consenso, ou seja, transfere-se a responsabilidade da tomada de decisão para as Cortes e se legitima seus métodos.

Outra face do avanço da judicialização é a supervisão e intervenção das Cortes no processo eleitoral, resultando, muitas vezes, no remodelamento desse processo. Medidas como determinação e imposição de regras eleitorais justas; regulação financeira de campanhas; interpretação e imposição de leis éticas que regulam a conduta pública de oficiais são algumas das intervenções mais comuns do judiciário sobre a organização dos pleitos legislativos e executivos. ${ }^{17}$

${ }^{16}$ TATE, C. Neal; VALLINDER, Torbjorn. The global expansion of judicial power.local. New York: New York University, 1995.

${ }^{17} \mathrm{O}$ exemplo do uso da arena judiciária pelas minorias parlamentares também é apontada por Taylor e por Ferejohn, como será tratado no ponto 4.2. 
Observando a expansão da jurisdição constitucional decorrente da Constituição de 1988, a autora afirma que a ascensão institucional do Poder Judiciário o tem colocado em situação estratégica, tanto na proteção dos direitos individuais e coletivos quanto no controle das políticas públicas e dos poderes constituídos, dando ao Supremo Tribunal Federal, em particular, uma posição de proeminência em relação aos outros poderes da república, como se constatam dos seus julgados que determinam os limites de atuação de estruturas do Poder Legislativo, como nas Comissões Parlamentares de Inquérito (CPIs) e no Conselho de Ética e Decoro Parlamentar da Câmara dos Deputados.

Finalmente, ainda há autores que notam que a influência das cortes fora do âmbito do processo judicial são absorvidas pelo Poder Legislativo. Taylor ilustra a capacidade dos membros do Judiciário de influenciar a discussão das políticas públicas antes de serem aprovadas:

Os juízes sinalizam suas preferências publicamente muito antes da aprovação final dos projetos, seja por meio de pronunciamentos públicos (caso do ministro Carlos Velloso na segunda tentativa de reforma da Previdência durante o governo Fernando Henrique) ou através de reuniões a portas fechadas entre Executivo e Judiciário (caso das medidas contra o apagão, que foram discutidas de antemão entre um representante do Executivo, Pedro Parente, e integrantes do STF). Esse tipo de sinalização calculada tem efeitos que antecipam o resultado final, inserindo os juízes no jogo e alterando a política pública resultante, muitas vezes sem o Judiciário precisar utilizar seus poderes formais. [...]

Isto é, mesmo sem usar seus poderes formais, como os de revisão constitucional, o Judiciário pode ter um impacto no momento da deliberação, eliminando algumas alternativas e constrangendo a liberdade de ação de outros atores políticos. ${ }^{18}$

${ }^{18}$ TAYLOR, Matthew Macleod. O judiciário e as políticas públicas no Brasil. Revista Dados, Rio de Janeiro, v. 50, n. 2, 2007. Disponível em: <www.scielo.br/pdf/dados/v50n2/ a01v50n2.pdf>. Acesso em: 14 ago. 2010. 
Faro de Castro afirma, no mesmo sentido, que até mesmo pronunciamentos não-jurisdicionais de magistrados, como entrevistas ou discursos de posse têm efeito político relevante. ${ }^{19}$

Concluindo seu levantamento sobre a jurisprudência do Supremo Tribunal Federal, Faro de Castro constata: "A análise dos acórdãos do tribunal revela que também a produção jurisprudencial rotineira do STF tem uma direção marcante na proteção de interesses privados e, portanto, de impacto negativo sobre a implementação de políticas públicas”. ${ }^{20}$

Desse modo, fica claro que a judicialização da política influencia concretamente nos resultados e na direção das políticas públicas, interferindo diretamente sobre as escolhas de alocação de recursos feitas pelos representantes eleitos.

\section{Problema: a escolha de políticas públicas pela via judicial é democrática?}

Está em pauta a representatividade democrática: o que significa eleger o judiciário como canal privilegiado de reivindicação em detrimento do legislativo? Essa nova disposição dos poderes políticos é ameaçadora do princípio democrático?

A usual crítica ao Judiciário enquanto poder não representativo é ilustrada por Matthew Macleod Taylor:

[...] frequentemente existe uma percepção pública de que há algo errado nessa atuação política dos tribunais no processo de formulação de políticas públicas. [...] a crescente judicialização e o conseqüente crescimento do impacto judicial em quase todo o mundo trouxeram consigo [...] uma crítica muito forte, por parte dos poderes eleitos, aos "legisladores não-eleitos.

${ }^{19}$ CASTRO, Marcus Faro de. O Supremo Tribunal Federal e a judicialização da política. Revista Brasileira de Ciências Sociais, São Paulo, v. 12, n. 34, p. 147-156, jul. 1997.

${ }^{20}$ CASTRO, Marcus Faro de. O Supremo Tribunal Federal e a judicialização da política. Revista Brasileira de Ciências Sociais, São Paulo, v. 12, n. 34, p. 147-156, jul. 1997. 
Para Aguiar, uma resposta efetiva precisa abordar a disparidade existente entre métodos de resolução de conflitos, uma vez que na arena legislativa predomina o princípio majoritário, enquanto no judiciário, o princípio da ponderação dos argumentos conforme sua qualidade:

Em uma comparação entre os métodos de resolução de conflitos legislativos e judiciários, Vallinder coteja diferenças fundamentais: a arena legislativa opera em termos de barganhas e troca de favores, enquanto o judiciário pesa os argumentos; no legislativo predomina o princípio majoritário, e no judiciário, a decisão dada por um juiz imparcial; um produz regras gerais e políticas públicas, e outro estabelece casos individuais; um aloca valores em virtude de uma solução possível politicamente, enquanto o outro se certifica dos fatos do processo e da lei adequada na busca da "única solução correta. ${ }^{21}$

Diante dessa diferença nos modelos de tomada de decisões (o legislativo, o quantitativo por maioria e o judiciário qualitativo pela força do argumento jurídico), Aguiar indica que a judicialização da vida política coloca em risco o modelo democrático do consenso - ou seja, a capacidade da sociedade de se autocompor, de produzir valores e arregimentar vontades na formação de uma unidade.

A dúvida sobre a representatividade do poder judiciário e, por conseguinte, sobre a legitimidade democrática do direito jurisprudencial, parte de uma questão de método. Em sua característica decisória, o método jurídico não teria a capacidade de produzir unidade social. Assim, “[...] ao revelar-se dissociado de um consenso, o direito jurisprudencial, com toda sua carga de criatividade, apresenta-se como instrumento antidemocrático e potencialmente tirânico". ${ }^{22}$

A autora questiona a ausência de limitação da atividade jurisdicional: “[...] o juiz, por meio de métodos criativos de decisão e incorporando critérios legais e

${ }^{21}$ CASTRO, Marcus Faro de. O Supremo Tribunal Federal e a judicialização da política. Revista Brasileira de Ciências Sociais, São Paulo, v. 12, n. 34, p. 147-156, jul. 1997.

22 CASTRO, Marcus Faro de. O Supremo Tribunal Federal e a judicialização da política. Revista Brasileira de Ciências Sociais, São Paulo, v. 12, n. 34, p. 147-156, jul. 1997. 
morais, exerce um poder político. Diante disso, perguntam-se, podem garantias de independência do juiz ser justificadas?” Ou seja, à medida que exerce um poder político e não se submete ao consenso, não deve o judiciário também ser limitado por outros poderes?" 23

Este artigo não tem a pretensão de debater tal questão, já que seria necessário abordar os mecanismos existentes de restrição da atividade jurisdicional, o que foge ao escopo do presente trabalho. ${ }^{24}$

Entretanto, tratamos de indicar adiante alguns aspectos que aumentam a representatividade do poder judiciário e sua adequação à democracia. Nesse aspecto, frutífera é a utilização do estudo de Jon Elster sobre as constituições como pré-compromissos para demonstrar que, quando o Judiciário determina ou revisa políticas públicas argumentando conforme a constituição, está em realidade apertando as amarras de Ulisses junto ao mastro para que não sucumba ao canto das sereias.

\subsection{Constituições como pré-compromissos a serem mantidos}

O título deste artigo (PARA REATAR ULISSES: A judicialização da política como mastro garantidor dos pré-compromissos constitucionais) é uma provocação. Faz referência à metáfora de que as Constituições seriam uma forma de autorrestrição imposta ao legislador ordinário pelo constituinte.

Explicando esta e outras metáforas, Jon Elster afirma que muitos autores argumentam que as Constituições políticas são dispositivos de pré-compromisso

\footnotetext{
${ }^{23}$ AGUIAR, Thais Florencio de. A judicialização da política ou o rearranjo da democracia liberal. Revista eletrônica semestral do programa de estudos pós-graduados em ciências sociais da PUC-SP, São Paulo, n. 2, Semestral, 2007.

${ }^{24}$ Sobre o tema, sugiro a leitura de KENNEDY,Duncan. Libertad y restricción en la decisión judicial: el debate con la teoría crítica del derecho (CLS). Bogotá: Siglo del Hombre, 1999. Disponível em: <http://duncankennedy.net/>. Acesso em: 12 ago. 2010.
} 
ou autorrestrição criados pelos políticos para se protegerem de suas próprias tendências previsíveis, a tomar decisões pouco sábias:

De acordo com John Potter Stockton, 'constituições são correntes com as quais os homens se amarram em seus momentos de sanidade para que não morram por uma mão suicida em seu dia de frenesi'. [...] De forma similar, Friedrich Hayek cita a visão de que uma constituição é um laço imposto por Pedro, quando sóbrio, sobre Pedro quando bêbado. Em uma declaração mais recente, Cass Sunstein escreve: 'As estratégias de pré-compromisso constitucionais poderiam servir para superar a miopia ou a fraqueza da vontade da coletividade. ${ }^{25}$

A mesma ideia pode ser encontrada na obra de Clèmerson Merlin Clève, afirmando que a missão do judiciário em nossa democracia é zelar pela observância dos direitos fundamentais para, “[...] no exercício da jurisdição constitucional, proteger a maioria permanente (Constituinte) contra a atuação desconforme da maioria eventual, conjuntural e temporária (legislatura)”. ${ }^{26}$

Elster faz ressalvas importantes de que se deve ter cautela para transferir conceitos usados para estudar indivíduos em escala ampliada, já que podemos ser induzidos em erro ao atribuir ao comportamento coletivo uma racionalidade não necessariamente verdadeira. Discutem-se as restrições constitucionais: como a exigência de quórum qualificado para emendá-la são casos de autorrestrição, ou seriam instrumentos para restringir os outros futuros congressistas. ${ }^{27}$

${ }^{25}$ ELSTER, Jon. Ulisses liberto. Estudos sobre racionalidade, pré-compromisso e restrições. São Paulo: Unesp, 2010. p. 119. O autor faz referência à comparação entre as constituições e a odisséia já no Tractatus Theologico-Politicus de Espinosa, assim como também cita John Potter Stockton, Friedrich Hayek e Cass Sunstein.

${ }^{26}$ CLÈVE, Clèmerson Merlin. A eficácia dos direitos fundamentais sociais. Revista Crítica Jurídica, Curitiba, n. 22, p. 17-29, jul./dez. 2003.

${ }^{27}$ Elster afirma no prefácio que teria sido bastante influenciado pelo comentário crítico feito por Jens Arup SEIP, de que "no mundo da política, as pessoas nunca tentam restringir a si próprias, mas apenas aos outros”. ELSTER, Jon. Ulisses liberto: estudos sobre racionalidade, pré-compromisso e restrições. São Paulo: Unesp, 2010. p. 7. 
Considerando a lógica da política de que a maioria restringe a minoria, afirma que os quóruns estabelecidos na Constituição podem servir para criar um efeito de estabilização da Constituição:

O efeito de estabilização da exigência de maiorias qualificadas para emendar a Constituição é talvez o aspecto mais importante do pré-compromisso constitucional. Ele fornece uma justificativa para o procedimento aparentemente arbitrário de permitir que uma pequena maioria na Assembléia Constituinte aprove um documento que só pode ser alterado por uma maioria substancialmente maior. ${ }^{28}$

Ademais, se as eleições para a Assembleia Constituinte se dão por sufrágio limitado, indica que a maioria dos constituintes naquele momento pode ter representado uma minoria da população, resguardando direitos ou privilégios contra uma maioria parlamentar mais ampla. ${ }^{29}$

Segundo Madison, 'em todos os casos em que a maioria está unida por um interesse ou paixão comum, os direitos da minoria estão em perigo' (I, p.135). Se os pobres ou os relativamente sem propriedades formassem uma maioria, seus interesses poderiam induzi-los a promulgar leis que fossem contrárias aos direitos de propriedade. ${ }^{30}$

Independentemente da motivação que leva o constituinte ${ }^{31}$ a impor obstáculos a alterações constitucionais, o mais importante parece ser que uma das boas

${ }^{28}$ ELSTER, Jon. Ulisses liberto: estudos sobre racionalidade, pré-compromisso e restrições. São Paulo: Unesp, 2010. p. 119.

${ }^{29}$ ELSTER, Jon. Ulisses liberto: estudos sobre racionalidade, pré-compromisso e restrições. São Paulo: Unesp, 2010. p. 125.

${ }^{30}$ ELSTER, Jon. Ulisses liberto: estudos sobre racionalidade, pré-compromisso e restrições. São Paulo: Unesp, 2010. p. 168.

${ }^{31}$ Sobre a Assembleia Constituinte, anote-se o interessante comentário de ELSTER de que "As Assembleias Constituintes encarnam, portanto, o que em outros textos chamei de 'paradoxo da democracia': cada geração quer ser livre para restringir suas sucessoras, mas não quer sofrer restrições por parte de suas predecessoras. [ ] os constituintes se vêem como superiores tanto aos regimes corruptos e ineficientes que estão substituindo quanto aos regimes movidos pelo interesse e pela paixão que os substituirão." ELSTER, Jon. Ulisses liberto: estudos sobre racionalidade, pré-compromisso e restrições. São Paulo: Unesp, 2010. 
consequências dessa prática é dar estabilidade. Ou seja, mitigar os efeitos perversos que poderiam advir das maiorias conjunturais e da influência das paixões, alterações passageiras na percepção das prioridades, permitindo a retomada do controle racional:

[...] a imposição de atrasos e de maiorias qualificadas está no núcleo do pré-compromisso constitucional. Atrasos e maiorias qualificadas são também usados, contudo, no processo político ordinário. Um argumento padrão em defesa do bicameralismo, como veremos, é que, ao atrasar o processo legislativo, permite-se que a paixão esfrie e que a razão (ou o interesse) retome o controle. ${ }^{32}$

Ao determinar que certas políticas públicas sejam realizadas de acordo ou em conformidade com o estabelecido na Constituição, o Poder Judiciário no exercício da jurisdição constitucional, desempenha a função de mastro garantidor de que os pré-compromissos constitucionais não serão abandonados.

Outra consequência salutar da judicialização da política, corre quando a determinação de políticas públicas pelo Poder Judiciário é utilizada por minorias parlamentares, governos estaduais, associações civis e indivíduos que encontram no acesso ao processo judicial um canal de participação e influência política. É o que se aborda adiante.

\subsection{A sociedade aberta dos intérpretes da constituição}

Outra abordagem - agora prescritiva - parte da análise das estratégias de argumentação que levam à decisão final. $\mathrm{O}$ fenômeno deve ensejar que os argumentos de luta democrática se estendam para dentro do processo judicial e permitam amplo debate de todos os interessados, o que vem sendo defendido por Peter Häberle em sua teoria de interpretação da Constituição.

32 ELSTER, Jon. Ulisses liberto: estudos sobre racionalidade, pré-compromisso e restrições. São Paulo: Unesp, 2010, p. 168. 
Häberle defende que as cortes constitucionais devem ampliar o debate sobre uma decisão a todos os atingidos por seus efeitos, os integrantes da chamada sociedade aberta dos intérpretes da constituição.

Fundada em estudos de hermenêutica, o autor influenciou em grande escala a atual política de julgamentos do STF para permitir que, ao interpretar a Constituição, qualquer pessoa interessada no resultado possa se manifestar antes da decisão final e seu argumento levado em conta.

Até pouco tempo imperava a idéia de que o processo de interpretação constitucional estava reduzido aos órgãos estatais ou aos participantes diretos no processo. Tinha-se, pois, uma fixação da interpretação constitucional nos 'órgãos oficiais', naqueles órgãos que desempenham o complexo jogo jurídico-institucional das funções estatais. Isso não significa que se não reconheça a importância da atividade desenvolvida por esses entes. A interpretação constitucional é, todavia, uma 'atividade' que, potencialmente, diz respeito a todos. Os grupos mencionados e o próprio indivíduo podem ser considerados intérpretes constitucionais indiretos ou a longo prazo. ${ }^{33}$

A tese permite que a jurisdição constitucional se torne um espaço de construção de um argumento e não simplesmente uma esfera decisional. A manifestação de opiniões diversas transforma o Judiciário em uma arena de debate privilegiado na qual a maioria não sai necessariamente vencedora, o acesso pelos mais diversos grupos de interesse torna plural o acesso à manifestação. $\mathrm{O}$ fato tem extremo poder simbólico para atribuir legitimidade ao Judiciário, eis que, em referência direta à democracia ateniense, relembra a isagoria instaurada a partir das constituições de Clístenes.

Foi seguindo o campo hermenêutico indicado por Häberle que a Lei 9.868/99 incluiu a possibilidade de realização de audiência pública no processo e julgamento da ação direta de inconstitucionalidade:

\footnotetext{
${ }^{33}$ HÄBERLE, Peter. Hermenêutica constitucional: a sociedade aberta dos intérpretes da Constituição: contribuição para a interpretação pluralista e 'procedimental' da Constituição. Trad. Gilmar Ferreira Mendes. Porto Alegre: S. A. Fabris, 2002. p.24.
} 
Art. $9^{\circ}$ Vencidos os prazos do artigo anterior, o relator lançará o relatório, com cópia a todos os Ministros, e pedirá dia para julgamento.

$\$ 1^{\circ}$ Em caso de necessidade de esclarecimento de matéria ou circunstância de fato ou de notória insuficiência das informações existentes nos autos, poderá o relator requisitar informações adicionais, designar perito ou comissão de peritos para que emita parecer sobre a questão, ou fixar data para, em audiência pública, ouvir depoimentos de pessoas com experiência e autoridade na matéria.

Demonstração da aproximação do Judiciário com os métodos do Legislativo pode ser encontrada na Ação Direta de Inconstitucionalidade (ADI) 3.510, de Relatoria do Min. Carlos Britto. Naquele processo, diante da inexistência de norma própria do Tribunal para regulamentar o procedimento da audiência pública, o Ministro Relator decidiu adotar as normas existentes no Regimento Interno da Câmara dos Deputados, o que passou a servir como precedente para as demais audiências públicas:

Ante a saliente importância da matéria que subjaz a esta ação direta de inconstitucionalidade, designei audiência pública para o depoimento de pessoas com reconhecida autoridade e experiência no tema $(\$$ $1^{\circ}$ do art. 9o da Lei n. 9.868/99). [...] Sem embargo, e conquanto haja previsão legal para a designação desse tipo de audiência pública $\left(\$ 1^{\circ}\right.$ do art. $9^{\circ}$ da Lei n. 9.868/99), não há, no âmbito desta nossa Corte de Justiça, norma regimental dispondo sobre o procedimento a ser especificamente observado.

Diante dessa carência normativa, cumpre-me aceder a um parâmetro objetivo do procedimento de oitiva dos expertos sobre a matéria de fato da presente ação. E esse parâmetro não é outro senão o Regimento Interno da Câmara dos Deputados, no qual se encontram dispositivos que tratam da realização, justamente, de audiências públicas (arts. 255 usque 258 do RI/CD). São esses os textos normativos de que me valerei para presidir os trabalhos da audiência pública a que me propus.

Outro ensinamento de Häberle é o de que a Constituição é mutável, isto é, de que sua interpretação deve ser modificada para atender às demandas do momento. A Constituição deve ser tida como um ponto de partida, não como um 
fim, devendo sua interpretação ser dinâmica e atendendo aos anseios atuais da população.

Enquanto a abertura do STF para as audiências públicas é bastante elogiada, a instabilidade das interpretações por sua possível constante modificação é objeto de ressalvas, como já exposto na introdução. O impacto do Judiciário na implementação das políticas públicas não é consenso entre os autores, Taylor elenca alguns dos estudos que alimentam o debate: ${ }^{34}$

[...] Arantes (2005:232) argumenta que o Judiciário tem tido um papel significativo na tomada de decisões, "acentuando ainda mais o modelo consensual da democracia brasileira”. Do outro, Koerner afirma que o Supremo Tribunal Federal - STF tem agido cautelosamente. Segundo o autor, no período pós-Constituinte, o STF "não funcionou como instituição contra- majoritária, que permitia o veto às reformas políticas, nem foi causador de incerteza e ingovernabilidade." 35

Alinhando-se com aqueles que veem um Judiciário cauteloso e cioso para não se indispor com o Executivo. Taylor afirma que:

o STF, em particular, tem agido de forma muito cautelosa e até conservadora para evitar alargar potenciais conflitos com o Executivo. Esse argumento é comum na literatura mundial sobre os tribunais, já que eles não podem atuar sem correr o risco de perder o seu poder para um Executivo cioso das próprias prerrogativas. ${ }^{36}$

\footnotetext{
${ }^{34}$ Marcus Faro de Castro e Werneck Vianna, em seus trabalhos de levantamento das decisões do STF, chegaram à conclusão de que havia impacto, normalmente em favor do cidadão individual, contra a fazenda pública. CASTRO, Marcus de Faro. O Supremo Tribunal Federal e a judicialização da política. Revista Brasileira de Ciências Sociais, São Paulo, v. 12, n. 34, p. 147-156, jul.1997; VIANNA, Luís Werneck et al. A judicialização da política e das relações sociais no Brasil. Rio de Janeiro: Revan, 1999.

35 TAYLOR, Matthew Macleod. O judiciário e as políticas públicas no Brasil. Revista Dados, Rio de Janeiro, v. 50, n. 2, 2007. Disponível em: <www.scielo.br/pdf/dados/v50n2/ a01v50n2.pdf>. Acesso em: 14 ago. 2010.

${ }^{36}$ TAYLOR, Matthew Macleod. O judiciário e as políticas públicas no Brasil. Revista Dados, Rio de Janeiro, v. 50, n. 2, 2007. Disponível em: <www.scielo.br/pdf/dados/v50n2/ a01v50n2.pdf $>$. Acesso em: 14 ago. 2010.
} 
Com relação a essa abertura do judiciário, algumas questões persistem: a) Pessoas comuns são capazes de prover mais e melhores informações ao Supremo do que integrantes do Congresso ou partidos políticos? b) Embora colhidas as opiniões, não há qualquer garantia de que o argumento será levado em conta e constará das razões de voto. Não deveria haver vinculação expressa para que sejam todos, senão acolhidos, ao menos juridicamente rejeitados?

\subsection{A politização do judiciário}

Em uma análise descritiva, a determinação de políticas públicas pelo Poder Judiciário é utilizada por minorias parlamentares, governos estaduais, associações civis e indivíduos, que encontram no acesso ao processo judicial um canal de participação e influência política.

John Ferejohn ${ }^{37}$ trabalha e diferencia os conceitos de judicialização da política e politização do Judiciário, indicando que a politização se dá quando atores externos ao Judiciário usam-no para atingir seus objetivos políticos.

O fenômeno também é esclarecido por Taylor, afirmando que a política pública pode ser contestada judicialmente por uma série de atores tanto do mundo político quanto da sociedade civil:

As regras institucionais, como constatamos anteriormente, podem dar poder a grupos minoritários que não agem no momento da deliberação entre Executivo e Legislativo, inserindo-os no debate pós-hoc e permitindo que usem os tribunais como um ponto de veto no jogo político. ${ }^{38}$

${ }^{37}$ FEREJOHN, John. Judicializing politics, politicizing law. Law and Contemporary Problems, v. 65, n. 3, p. 41-69, 2002. Disponível em: <http://www.law.duke.edu/>. Acesso em: 15 ago. 2010.

38 TAYLOR, Matthew Macleod. O judiciário e as políticas públicas no Brasil. Revista Dados, Rio de Janeiro, v. 50, n. 2, 2007. Disponível em: <www.scielo.br/pdf/dados/v50n2/ a01v50n2.pdf>. Acesso em: 14 ago. 2010. 
Taylor relata ainda um caso prático em que a Ordem dos Advogados do Brasil, não tendo representação política para fazer prevalecer sua opinião, o fez em juízo, obtendo-se por meio de uma ADI a defesa de seu interesse:

Para ilustrar as consequências de deixar o Judiciário fora da análise da tomada de decisões pelo sistema político brasileiro, ofereço uma visão heurística e simplificada da reforma agrária de 1999-2000. Nesse caso, o governo Fernando Henrique tentou, com algum sucesso, achar um espaço de comum acordo entre os donos de terra e o Movimento dos Sem-Terra - MST. A legislação proposta pelo governo federal estabelecia limites para compensações excessivas em expropriações de terra, mas também criou importantes restrições às invasões empreendidas pelos sem-terra. [...]

Faltou, no entanto, incorporar à proposta os interesses de um jogador de veto em potencial, a Ordem dos Advogados do Brasil - OAB. Embora não tivesse representação direta no Congresso - e se tivesse, mal poderia usá-la por se tratar de uma medida provisória -, a OAB teve acesso ao ponto de veto oferecido por ser um ator com legitimação ativa para apresentar Adins. Isso permitiu que a OAB se inserisse no debate sobre a reforma através do STF. Quando a medida provisória foi decretada, a $\mathrm{OAB}$ imediatamente contestou vários elementos da nova política por meio de Adin. A OAB teve sucesso em um ponto de especial interesse a seus membros: o STF deferiu em parte o pedido de liminar contra os limites decretados pelo governo para os honorários advocatícios em casos de expropriação.

Como resultado, a $\mathrm{OAB}$ conseguiu mudar a política pública [...], transferindo o resultado de um ponto próximo às preferências centrais do governo para um ponto mais próximo das preferências dela, eliminando as novas limitações propostas pelo governo no tocante às restrições aos honorários advocatícios. ${ }^{39}$

Assim como está descrito, a utilização do Poder Judiciário como arena de disputa política é uma distorção indesejável da influência do Judiciário nas políticas públicas. Isso porque faz com que o embate político se dê para um ambiente

\footnotetext{
${ }^{39}$ TAYLOR, Matthew Macleod. O judiciário e as políticas públicas no Brasil. Revista Dados, Rio de Janeiro, v. 50, n. 2, 2007. Disponível em: <www.scielo.br/pdf/dados/v50n2/ a01v50n2.pdf $>$. Acesso em: 14 ago. 2010.
} 
de confronto, afastando os atores do caminho desejável do consenso, bem como prolongando indefinidamente disputas sobre temas sensíveis ou até mesmo reacendendo a discussão sobre assuntos já debatidos e encerrados.

Algumas das táticas - de efeito perverso - utilizadas por atores políticos é descrita em detalhes por Taylor e por Werneck Vianna:

Outro mecanismo tático para os atores políticos: a incerteza gerada pela protelação de uma decisão definitiva através do recorrente uso de diversas instâncias ou recursos no Judiciário (Quadro 1). Essa segunda tática não requer que os argumentos legais necessariamente estejam a favor do grupo de oposição: na luta contra as privatizações nos anos 1990, por exemplo, muitas vezes a oposição buscou encontrar um juiz que simpatizasse o suficiente com a questão para emitir uma liminar contra os leilões, mesmo sabendo que ela seria derrubada em seguida, diante das leis em vigor. Em outras palavras, não tem sido raro a oposição política usar os tribunais mesmo sabendo que não tem condições legais de vencer a briga: o Judiciário também serve para as oposições mostrarem serviço, protelando a implementação de políticas públicas contrárias aos interesses de seus seguidores e chamando a atenção pública para sua oposição. Nessa linha, Werneck Vianna et alii explicam a tendência dos partidos políticos de entrar com recurso no Judiciário 'visando apenas marcar uma posição de contraste com a maioria e demonstrar aos seus aderentes e ao público em geral a sua disposição de esgotar, no terreno institucional, todas as possibilidades abertas à sua intervenção' (1999:127) um ponto de veto no jogo político. ${ }^{40}$

Neste aspecto, os tribunais ampliam o leque de atores que podem influenciar a implementação de políticas públicas - ainda que já tenham sido aprovadas por amplas maiorias legislativas. ${ }^{41}$ Ainda, Taylor afirma que "os grupos de interesse

40 TAYLOR, Matthew Macleod. O judiciário e as políticas públicas no Brasil. Revista Dados, Rio de Janeiro, v. 50, n. 2, 2007. Disponível em: <www.scielo.br/pdf/dados/v50n2/ a01v50n2.pdf>. Acesso em: 14 ago. 2010.

${ }^{41}$ TAYLOR, Matthew Macleod. O judiciário e as políticas públicas no Brasil. Revista Dados, Rio de Janeiro, v. 50, n. 2, 2007. Disponível em: <www.scielo.br/pdf/dados/v50n2/ a01v50n2.pdf>. Acesso em: 14 ago. 2010. 
procuram o local institucional mais favorável para contestar as políticas públicas ("venue-seeking”), seja esse local o Judiciário, as agências reguladoras ou as burocracias específicas" ${ }^{42}$ Assim, o autor constata que por conta da capacidade do Judiciário de impor suas decisões, ele vem sendo usado crescentemente como uma 'venue' para a contestação das políticas públicas.

A despeito dos abusos, impedir o uso do Judiciário por parte de atores políticos não é solução que se cogite. Isto porque não há como aferir se uma determinada ação trata de demanda legítima ou mera manobra política e qualquer obstáculo que porventura se adote para evitar o segundo caso pode violar o princípio da inafastabilidade do Judiciário, tendo como consequência o risco de afastar as minorias que efetivamente buscam nele o espaço de reivindicação que lhes é negado na esfera parlamentar.

\subsection{O judiciário como ator com poder de veto}

Em sua obra recentemente versada para o português, George Tsebelis desenvolve um instrumento para permitir a comparação entre instituições políticas de diferentes países, levando em conta a relação entre a estabilidade decisória e o número de "atores individuais ou coletivos cujo acordo é necessário para uma mudança do status quo" - os atores com poder de veto. ${ }^{43}$

Embora os atores com poder de veto sejam normalmente os indicados na Constituição (atores institucionais), conforme TSEBELIS, o Poder Judiciário pode se transformar em um "ator com poder de veto" adicional. ${ }^{44}$

${ }^{42}$ TAYLOR, Matthew Macleod. O judiciário e as políticas públicas no Brasil. Revista Dados, Rio de Janeiro, v. 50, n. 2, 2007. Disponível em: <www.scielo.br/pdf/dados/v50n2/ a01v50n2.pdf>. Acesso em: 14 ago. 2010.

${ }^{43}$ TSEBELIS, George. Atores com poder de veto: como funcionam as instituições políticas. São Paulo: FGV, 2010. p. 41.

${ }^{44}$ No Brasil, teríamos 3 atores com poder de veto: Presidente da República, Câmara de Deputados e Senado Federal. 
Dito de outro modo, em países onde há o exercício da jurisdição constitucional, com a possibilidade de influir na arena decisória do jogo político - e consequentemente, redefinindo a alocação de recursos públicos -, o Poder Judiciário é somado à lista dos atores com poder de veto:

[...] a evidência empírica corrobora a suposição de que a independência do Judiciário aumenta como função dos atores com poder de veto.

Apesar de estar claro que o Judiciário de um país não é um ator com poder de veto, quando realiza interpretações estatutárias, porque ele pode ser sobrestado pela legislação, o oposto também é verdade em relação à interpretação constitucional.

Stone-Sweet (2000) afirma que a introdução do escrutínio de tribunais constitucionais alterou profundamente o papel tanto dos tribunais quanto do Legislativo e introduziu uma interação constante entre as duas instituições. Por essa interação, as legislaturas estão sempre conscientes de que suas ações podem ser sobrestadas pelos tribunais constitucionais e algumas vezes até mesmo pedem instruções aos tribunais para imunizar suas decisões contra uma revogação judicial. ${ }^{45}$

De acordo com as próprias conclusões traçadas por Tsebelis, a inclusão do Judiciário como mais um ator com poder de veto influencia para aumentar a estabilidade decisória, já que quanto maior o número de atores, maiores serão os obstáculos para efetuar mudanças no status quo.

Consequência relevante dessa assertiva para o tema deste trabalho é que o Judiciário, enquanto ator com poder de veto, colabora para dar estabilidade e manter o status quo.

Em um modelo idealizado, por meio da jurisdição constitucional, opera-se uma garantia da vontade da Constituição, ainda que em oposição à vontade da maioria legislativa, trazendo obstáculos à mudança de rumos e prioridades.

45 TSEBELIS, George. Atores com poder de veto: como funcionam as instituições políticas. São Paulo: FGV, 2010. p. 317. 
Entretanto, Tsebelis aponta que pode ocorrer que por conta das regras usuais de seleção e ingresso, os integrantes das Cortes e Tribunais Constitucionais não marquem opinião destoante do conjunto já estabelecido no embate político, optando por se manter alinhados às opiniões dos atores políticos que os selecionaram.

Quando esse fenômeno ocorre, Tsebelis afirma que os efeitos das escolhas manifestadas pelas Cortes Constitucionais são mitigados. Sendo coincidentes com a de atores com poder de veto já existente, são absorvidos por estes sem influir quaisquer modificações (seja aumento, seja diminuição) na estabilidade decisória e na manutenção do status quo. ${ }^{46}$

\section{Conclusões}

A partir da revisão de literatura sobre o fenômeno da judicialização da política, podemos perceber que, por meio da jurisdição constitucional, o Poder Judiciário no Brasil tem influenciado concretamente nos resultados e na direção das políticas públicas.

A despeito de reticências na doutrina, o protagonismo judicial tem sido salutar, em parte por conta de um esforço considerável de legitimidade representativa, no qual o STF busca incluir um maior número de atores no processo decisional, o que se insere no quadro teórico da sociedade aberta dos intérpretes da constituição.

Defendemos que são benéficos os efeitos deste protagonismo judicial, quando coerentes com os valores constitucionais, garantindo a manutenção dos pré-compromissos estabelecidos e atribuindo estabilidade decisória ao se comportar como ator com poder de veto.

Com relação aos limites da atuação do Judiciário, não há resposta definitiva ou estrutura atual que garanta sua contenção em termos de políticas públicas. No

${ }^{46}$ TSEBELIS, George. Atores com poder de veto: como funcionam as instituições políticas. São Paulo: FGV, 2010. p. 343. 
entanto, ainda assim o Judiciário desempenha um papel importante ao fornecer um espaço para o embate democrático, conforme afirma Taylor, citando Vianna:

[...] há uma certa ambigüidade que sempre cercará a atuação do Judiciário na política, tanto em termos da teoria democrática quanto na questão da formulação efetiva e eficaz das políticas públicas. É muito comum em todo o mundo reclamar da interferência de juízes na política. Mas é importante reconhecer, como o fazem Werneck Vianna e Burgos (2005:781-782), o papel democratizante do Judiciário, agindo tanto como um "muro de lamentações" quanto como "uma efetiva arena para o exercício da democracia”, em uma democracia na qual a relação entre Executivo e Legislativo foge do ideal. ${ }^{47}$

Por fim, a despeito do fenômeno indesejável da politização do judiciário (o uso dos Tribunais para concretizar manobras por atores políticos), o Poder Judiciário pode vir a se tornar, legitimamente espaço de exercício democrático, representando a vontade de grupos minoritários sem acesso às estruturas políticas tradicionais.

\section{To rebound Ulysses: the 'judicialization' of politics as a mast where constitutional pre-commitments are tied to}

\section{Abstract}

Since the 1988 Constitution of the Federative Republic of Brazil, expansion of legal instruments of protection and accommodation of a greater number of interests and orientations have led to the an increase of court ruling on political matters. This article proposes a review in the field of constitutional law and political science to study the legitimacy of the judiciary and its limits, when its decisions affect the allocation of public resources - a typical political issue. The legal method is not able to produce a social unit, as its decision-making process do not

47 TAYLOR, Matthew Macleod. O judiciário e as políticas públicas no Brasil. Revista Dados, Rio de Janeiro, v. 50, n. 2, 2007. Disponível em: <www.scielo.br/pdf/dados/v50n2/ a01v50n2.pdf>. Acesso em: 14 ago. 2010. 
depends of political consensus. This article combines Political Science studies as well as Contemporary Constitutionalism authors, building a bridge that relies the contributions of Jon Elster and George Tsebelis (mainly in their analysis of political institutions with the constitutional theories that deal with the democratization of the judiciary) and the work of German Constitutionalist Peter Häberle (and his theory of the open society of constitution interpreters). This work aims to debate the issues of the current democratic arrangement in Brazil (post-88) and the search for legitimacy (in the sense of representativeness) of the Judiciary Power.

Keywords: Legalization of politics. Judicial prominence. Democracy..

\section{Referências}

AGUIAR, Thais Florencio de. A judicialização da política ou o rearranjo da democracia liberal. Revista eletrônica semestral do programa de estudos pósgraduados em ciências sociais da PUC-SP, São Paulo, n. 2, Semestral, 2007.

CAPPELLETTI, Mauro. Juízes legisladores? Trad. Carlos Álvaro de Oliveira. Porto Alegre: S. A. Fabris, 1999.

CASTRO, Marcus Faro de. O Supremo Tribunal Federal e a judicialização da política. Revista Brasileira de Ciências Sociais, São Paulo, v. 12, n. 34, p. 147-156, jul. 1997.

CLÈVE, Clèmerson Merlin. A eficácia dos direitos fundamentais sociais. Revista Crítica Jurídica, Curitiba, n. 22. p.17-29, jul./dez. 2003.

DAHL, Robert. Decision-making in a democracy: the Supreme Court as a National Policy-Maker. Journal of Public Law, v.6, 1957. In: TAYLOR, Matthew Macleod. O judiciário e as políticas públicas no Brasil. Revista Dados, Rio de Janeiro, v. 50, n. 2, 2007. Disponível em: <www.scielo.br/pdf/dados/v50n2/a01v50n2.pdf >. Acesso em: 14 ago. 2010.

ELSTER, Jon. Ulisses liberto: estudos sobre racionalidade, pré-compromisso e restrições. São Paulo: Unesp, 2010. 
FEREJOHN, John. Judicializing politics, politicizing law. Law and Contemporary Problems, v. 65, n. 3, p. 41-69, 2002. Disponível em: <http://www.law.duke.edu/>. Acesso em: 15 ago. 2010.

HÄBERLE, Peter. Hermenêutica constitucional: a sociedade aberta dos intérpretes da Constituição: contribuição para a interpretação pluralista e 'procedimental' da Constituição. Trad. Gilmar Ferreira Mendes. Porto Alegre: S. A. Fabris, 2002.

HAMILTON, Alexander. The Federalist n. 78: the judiciary department. Independent Journal, 14 Jun. 1788. Disponível em: <http://www.constitution.org/ fed/federa78.htm>. Acesso em: 10 ago. 2010.

KENNEDY,Duncan; LÓPEZ, Diego Eduardo. trans, Libertad y restricción en la decisión judicial: el debate con la teoría crítica del derecho (CLS). Bogotá: Siglo del Hombre, 1999. Disponível em: <http://duncankennedy.net/>. Acesso em: 12 ago. 2010 .

TATE, Neal; VALLINDER, Torbjorn. The global expansion of judicial power. New York: New York University, 1995.

TAYLOR, Matthew Macleod. O judiciário e as políticas públicas no Brasil. Revista Dados, Rio de Janeiro, v. 50, n. 2, 2007. Disponível em: <www.scielo.br/pdf/dados/ v50n2/a01v50n2.pdf>. Acesso em: 14 ago. 2010.

TSEBELIS, George. Atores com poder de veto: como funcionam as instituições políticas. São Paulo: FGV, 2010.

VIANNA, Luís Werneck et al. A judicialização da política e das relações sociais no Brasil. Rio de Janeiro: Revan, 1999. 


\section{Para publicar na revista Brasileira de Políticas Públicas, acesse 0 endereço eletrônico www.publicacoesacademicas.uniceub.br. Observe as normas de publicação, para facilitar e agilizar o trabalho de edição.}

